\title{
A Rússia Vestida de Chamas Purificadoras
}

\author{
Rafael Bonavina
}

Resumo: No presente artigo, apresentamos a tradução, com breves explicações a respeito da fundamentação teórica utilizada em seu preparo, e uma sucinta análise do poema "Terra Natal", de Andrei Biély.

Palavras chave: Século XX; Poesia russa; Andrei Biély; Simbolismo russo; Sóphia.

\section{O batismo em fogo}

Embora não existam chaves michas para a leitura da poesia de Andrei Biély (1880-1934), a imagem da eterna feminilidade ${ }^{1}$ abre diversas portas da literatura simbolista russa. Ela é um dos pontos comuns entre todos esses escritores, ou, nas palavras de Victor Terras, “essa visão da 'Dama Mais Bela,' a 'Mulher Vestida do Sol,' tornou-se um símbolo evocativo para diversos simbolistas (Biély inclusive)" (TERRAS, 1985, p. 45, tradução nossa) ${ }^{2}$.

Pouco divulgada, a produção de Andrei Biély é diversa e vasta. Por exemplo, durante "o período entre 1903 a 1910 [...] ele publicou mais de duzentos artigos, resenhas de livros, e ensaios, bem como três coleções de poesia" (TERRAS, 1985, p. 45, tradução nossa) ${ }^{3}$. Perdido nesse labirinto de folhas de papel e carente de um caminho determinado, o leitor precisa, ao menos, de uma estrela distante para guiar-se. Para Carpeaux, as obras-primas de Biély são: "Sinfonia (1902); Ouro no

1 Em russo, Viétchnaia Jenstviennost'.

2 [This vision of a "Lady Most Beautiful," a "Woman Clothed in the Sun," became an evocative symbol for several symbolists (Bely included)].

3 [The period 1903 to 1910 was an astonishingly productive one for Bely; he published over two hundred articles, book reviews, and essays, as well as three collections of poetry]. 
Azul (1904); Sinfonia nórdica (1904); A Volta (1904); Cinza (1908); Urna (1909); Pomba de prata (1910); Peterburg (1916); Kotik Letaiev (1922); Recordações sobre A. A. Blok (1923); Moscou (1926)." (CARPEAUX, 2014).

Nascido em 25 de Outubro de 1880, Boris Nikoláievitch Bugáiev era o único filho de Nikolai Vassílievitch Bugáiev, um renomado matemático da Universidade de Moscou, e sua esposa, Aleksandra Dmitrievna. "Eles eram um casal estranho: o excêntrico, autocrático, porém brilhante pai estava profundamente dedicado às ciências naturais e às suas próprias matemáticas" (TERRAS, 1985, p. 45, tradução nossa $)^{4}$, enquanto a mãe era uma mulher dedicada às artes, com certo talento musical, e uma ferrenha crítica da racionalidade. Esse embate da "ordem harmônica contra desordem caótica, criação contra destruição, amor contra ódio, moralidade versus amoralidade, unidade e comunhão contra desintegração e estranhamento" (TERRAS, 1985, p. 45, tradução nossa) ${ }^{5}$ são alguns dos centros de gravitação da imagética bielyana. O poema traduzido ao final demonstra algumas manifestações dessas contradições, dessa "visão científica baseada no caos cósmico" (TERRAS, 1985, p. 45, tradução nossa) $)^{6}$, de ausente causalidade lógica, a partir da qual, sozinho, o homem cria um sentido para si.

Em 1903, Boris Bugáiev obtém seu diploma em ciências naturais, porém o destaque maior nesse período cai sobre as suas Sinfonias, a Primeira desse mesmo ano e a Segunda do anterior, contrariando o esperado. "Graças ao seu caráter experimental e 'decadente', ele as publicou sob o pseudônimo, talvez evitando constranger o pai” (TERRAS, 1985, p. 45, tradução nossa) 7 . O pseudônimo de Andrei Biély surge por sugestão de Vladimir Solovióv (1853-1900), velho amigo da família.

Como afirma John Noyce, "ao final do século dezenove, o filósofo Vladimir Solovióv desenvolveu a noção de Sóphia baseado nas suas próprias visões e nos escritos teológicos anteriores de Böhme e seus sucessores." (NOYCE, 2007, pp. 6-7, tradução nossa) $)^{8}$. Mais especificamente, a respeito dessas "visões", Terras

4 [They were an ill-matched pair: the eccentric, autocratic, but brilliant father was deeply committed to the natural sciences and to his own mathematics].

5 [harmonious order versus chaotic disorder, creation versus destruction, love versus hatred, morality versus amorality, unity and community versus disintegration and estrangement].

6 [A scientifically based vision of cosmic chaos].

7 [Owing to their experimental, "decadent" character. he published them under a pseudonym, perhaps to avoid embarassing his father].

8 [notion of Sophia based on his own personal visions and on the earlier theological writings of Boehme and his successors]. 
afirma que Biély fora influenciado pela "compreensão de Solovióv do processo histórico e cosmológico como um movimento de religação com Deus" (TERRAS, 1985 , p. 45, tradução nossa) $)^{9}$. Vale lembrar que a própria palavra "religião" tem como raiz a palavra latina religio de etimologia obscura, provavelmente advinda de religare, reconexão, reunião.

Essa figura feminina dedilhada na lira do filósofo Solovióv ecoará nos acordes de outros autores, como Biély, Blok, e Merejkovsky. Como demonstra Noyce, as raízes da imagem de Sófia não nascem em Solovióv, datam de séculos antes, por exemplo, há a construção de Hagia Sofia, a Basílica de Santa Sofia. Ao longo dos séculos, bem como dos poemas escritos dedicados à Sófia, a imagem dela passa de uma pessoa tangível - por vezes atribuída à esposa de Solovióv para uma abstração arcana e baça.

No caso de Andrei Biély, a mudança atravessa diversos estágios, passando por "Sófia, Virgem Radiante, Donzela dos Portões Arco-Íris" (NOYCE, 2007, p. 8 , tradução nossa $)^{10}$, inclusive pela forma de Alma do Mundo, que seria "a matéria comum que liga todas as criaturas, que, certa feita, separaram-se voluntariamente de Deus (que em seu amor dá liberdade à Criação), mas que é religada ao Logos Divino através de Cristo" (TERRAS, 1985, p. 45, tradução nossa) ${ }^{11}$.

Aos poucos, em sua interpretação de Sófia, Biély transforma a Eterna Mulher na Mulher Vestida do Sol, retirada ipsis literis da Bíblia católica. João relata uma das revelações do fim dos tempos em que "[...] viu-se um grande sinal no céu: uma mulher vestida do sol, tendo a lua debaixo dos seus pés, e uma coroa de doze estrelas sobre a sua cabeça." (BÍBLIA, Apocalipse, 12, 1).

A polifórmica Mulher não se cristaliza na bíblica "Mulher vestida do Sol", ela se recusa a engessar-se. No poema Terra Natal, de agosto de 1917, Sófia assume a forma da própria Rússia - que também é um substantivo feminino em russo como "Messias do dia que virá". Ao olhar para o poema, isolado do contexto de produção, talvez o leitor considere uma ode ao mito da sacra missão russa, mas ao levar em conta que ao final do ano começaria o ciclo de revoluções na Rússia, nota que o poeta dialoga, também, com os eventos de sua realidade histórica. Não se trata apenas de uma visão apocalíptica em sentido estrito, escatológico, mas

9 [Solovyov's understanding of cosmological and historical process as a movement toward reunification with God].

10 [Sophia, Radiant Virgin, Maiden of the Rainbow Gates].

11 [the common subject uniting all creatures, which once voluntarily separated itself from God (who in his love grants creation freedom) but which is linked again to the Divine Logos through Christ]. 
de uma ode à mudança. O eu-lírico ordena que se dobrem os joelhos "diante do turbilhão de labaredas", e vale um momento de reflexão a imagem das labaredas, pois estas tem uma dupla significação.

Geralmente, o fogo relaciona-se aos conceitos de destruição ou de purificação. Dentro desta concepção está o ambíguo fogo bíblico, ora ligado às desgraças, ora às sarças ardentes. Se tomarmos o livro de João, pois há evidente intertextualidade, encontraremos a imagem do lago de fogo. Ser lançado nele "é a segunda morte" (BÍBLIA, Apocalipse, 21, 8), uma morte da qual não escapam o falso profeta, a besta, o Demônio, a morte, e o próprio inferno. E a partir dessas chamas, nascem "um novo céu, e uma nova terra. Porque já o primeiro céu e a primeira terra passaram, e o mar já não existe.” (BÍBLIA, Apocalipse, 21,1). O transformador fogo bíblico será tomado por Biely e estará diretamente relacionado com a manifestação da "Mulher Vestida do Sol" no poema, a Rússia. A mudança trazida pela Rússia-Sófia, portanto, trata-se da mudança prometida pela revolução social, "o dia que virá". A respeito da destruição, Meletínski afirma que, "[...] 'A destruição e o caos' remetem àquilo que encarnavam/personificavam no mito os monstros ctônicos" (MELETÍNSKI, 1994, p. 217), porém o fogo, e, portanto, a destruição, emana da própria Rússia, dessa manifestação ambígua do Eterno Feminino, ou da Grande Mãe, em que estão representadas concomitantemente os arquétipos de amante e feiticeira. A Rússia é o uroboros, ou seja, ao mesmo tempo, é a heroína engolida e o ser ctônico que o engole. "O uroboros e sua soberania estão estritamente ligados com a imagem da Grande Mãe [...] associada com a terra e com a natureza absolutamente inconsciente em contraposição à cultura." (MELETÍNSKI, 1994, p. 25).

Seguindo o próprio conselho de curvar-se perante o "turbilhão de labaredas", brada o eu-lírico: enlouquece, Rússia, tornando-me pó! Demonstrando sua convicção na "concepção de Steiner de um processo de evolução cósmica polvilhado por períodos violentos de transição" (TERRAS, 1985, p. 46, tradução nossa $)^{12}$. No entanto, faz-se necessário apontar que no ensaio escrito em 1917 , mesmo ano de publicação do poema, intitulado Revolução e Cultura (Revoliútsia i Kultura), Biély insiste que o determinismo econômico

não traz em si nenhum espírito revolucionário, mas é meramente uma forma de academicismo que deturpa a essência humana. $\mathrm{O}$ verdadeiro progresso não é o desenvolvimento econômico, mas a elevação espiritual.

12 [Steiner's conception of a process of cosmic evolution punctuated by violent periods of transition]. 
A humanidade vai transcender da necessidade para a liberdade, não pela operação de leis econômicas, mas através da criatividade estética e espiritual (ROSENTHAL, 1980, p. 190, tradução nossa) ${ }^{13}$.

Assim, o poema não se trata de militância bolchevista panfletária, é um panegírico à mudança espiritual e às promessas de libertação implicadas na revolução social, física. Ainda afirma Rosenthal que "comparando o espírito revolucionário a um cometa, ele fala sobre suas origens na 'estrela inamovível dentro de nós' [...] e sobre como, na colisão da revolução contra a cultura, os dois tornam-se um” (ROSENTHAL, 1980, p. 190). Ou seja, uroboros termina de engolir a si mesmo e transforma-se em uma paradoxal mônada que, ao mesmo tempo, contém e é contida.

\section{As bem-ditas palavras}

Evitando o conforto da penumbra do silêncio, nesta parte do trabalho, pretendemos trazer à luz alguns dos muitos nós górdios encontrados nesta tradução que afloraram no contato direto entre dois povos tão distantes. Tentaremos não utilizar palavras estrangeiras para conduzir essa discussão, exceto no caso do neologismo na segunda estrofe, pois este será inevitável. Não nos debruçaremos exaustivamente sobre todas as dificuldades tradutológicas, pois foram muitas, e isso só cansaria o leitor. "Em todo caso, [...] mais vale ler em tradução do que não ler de todo ou fingir que se leu no original.” (RÓNAI, 2012, p. 66).

A tradução de um poema em russo implica em dois problemas: o de ser um poema, e o de estar em russo. $\mathrm{O}$ primeiro destes, trataremos mais adiante. $\mathrm{O}$ segundo, agora. A língua russa, por exemplo, não tem artigos. Então, se "existisse tradução literal, isto é, fidelidade unilateral, o problema nem surgiria e deixaríamos de pôr o artigo ao longo de toda a obra" (RÓNAI, 2012, p. 22). No entanto, se o tradutor fizesse isso, o resultado causaria otite. O tradutor terá de optar por colocar o artigo definido, ou indefinido, ou não usar nenhum. "Cada um desses casos (e são milhares num só livro) é resolvido segundo as leis orgânicas do português; o original não fornece indicação alguma." (RÓNAI, 2012, p. 22). A teoria de uma tradução verdadeiramente fiel cai por terra. Sem o acalento de poder apontar para o original e esconder-se por trás das palavras de outrem e de uma língua desco-

13 [bears no revolutionary spirit but is merely a form of scholasticism that warps the human essence. True progress is not economic improvement but spiritual uplift. Humanity will ascend from necessity to freedom, not by the operation of economic laws, but through spiritual and aesthetic creativity]. 
nhecida, o tradutor torna-se um nervo exposto. Porém não é necessário que ele sinta-se assim, pois "a fidelidade alcança-se muito menos pela tradução literal do que por uma substituição contínua. A arte do tradutor consiste justamente em saber quando pode verter e quando deve procurar equivalências." (RÓNAI, 2012, p. 24). Mais, "como não há equivalências absolutas, uma palavra, uma expressão ou frase do original podem ser frequentemente transportadas de duas maneiras, ou mais, sem que se possa dizer qual das duas é a melhor." (RÓNAI, 2012, p. 24).

Descartada a fidelidade fanática, tampouco a tradução proposta se baseia "naquilo que o autor queria dizer", afinal: "Se ele quisesse dizer, teria dito" (SARTRE, 1951 apud CAMPOS, 2013, p. 4), inclusive de maneira oblíqua, se necessário. Outra distorção que permeia os meandros tradutológicos é a de ser dever do tradutor a reprodução do "sentido do texto", "a mensagem". Mas de nada adiantaria “reproduzir apenas o 'conteúdo', a 'mensagem' de um poema, pois, a nosso ver, limitar a tradução de poesia a este aspecto seria um empobrecimento e uma deformação.” (CAMPOS et al., 1968, pp. 14-15). Assim, não nos fixaremos no campo da versão fiel e literal, nem na recriação absolutamente desprendida do original, de uma liberdade descompromissada. Há "entre a tradução literal e a tradução livre uma terceira, a literária, precisamente aquela que devemos propor como objetivo.” (RÓNAI, 2012, p. 48). Esta é a tradução que se busca na presente proposta.

Apontado no início, o problema de se tratar de um poema a ser traduzido está em que ele não é feito apenas de um sentido, ou seja, não é constituído puramente de informações semânticas. Nele existem ritmo, antíteses, sonoridade, choques, imprevisibilidades, características estéticas, estilísticas, nada semânticas. São justamente essas informações estéticas que a presente tradução busca recriar. Informação estética pode ser definida como aquela que "transcende a semântica, no que concerne à 'imprevisibilidade, à surpresa, à improbabilidade da ordenação de signos"' (CAMPOS, 2013, p. 2). Seria descabido pensar que o tradutor abordaria um poema de Olavo Bilac da mesma maneira que um poema de Khliébnikov ou Du Fu.

Entre os problemas encontrados na tradução deste poema, há, por exemplo, a dificuldade lexical do último verso da primeira estrofe. Nele há um imperativo em segunda pessoa. O original traz um palavra estranha para a língua portuguesa que significa "andar com filosofice" (VOINOVA, STARIETS et al, 1975, p. 811), ao qual foi adicionado o prefixo semelhante o "des-". A opção foi pela forma imperativa do verbo "enlouquecer". Apesar da construção pouco usual em russo, ela não é tão estranha quanto à tradução fiel em português, que causaria espanto; algo como "desfilosofizar-se". 
Um caso fonológico pode ser encontrado no último verso da terceira estrofe. No original não se tratavam de "cósmicas semanas", mas de "cósmicos dias". A troca parece pouco significativa, embora a opção feita dê a impressão de um período mais longo, porém foi feita com o intuito de manter a sonoridade. No original, a rima é intercalada entre as vogais brandas "ie" e "ij", de sutil diferença, reproduzidas na tradução através da alternância dos sons "a" e “ã". Parece grande a diferença entre um "a" aberto e um nasalizado, mas se um estrangeiro pouco habituado à fonética brasileira for questionado, terá dificuldade de distinguir um do outro em primeiro momento e muito mais problemático será o trava-língua de reproduzir tais sons.

A quarta estrofe precisou de um procedimento para suprir a ausência de declinação, acrescido do tradicional malabarismo com vírgulas. Originalmente, os dois primeiros versos da tradução encontravam-se ao final da estrofe, mas dessa maneira a construção ficaria demasiado obscura para o leitor. Nessa mesma passagem, ligado ao substantivo "Cristo", há o particípio do verbo "descer". Mas "Cristo descido" seria mais um caso agudo de otite; "Cristo caído", uma antítese muito distante do original. Então optou-se pelo uso do antônimo de “ascender aos céus", "descender à terra”, e sua forma de particípio, "descendido", anteposta.

Semelhante é a dificuldade da penúltima estrofe: a construção feita por Biély depende muito das declinações para ser compreendida e, mesmo assim, é confuso pela coincidência da terminação semelhante entre o plural dos casos prepositivo e o genitivo em russo. Ao contrário da solução anterior, optamos por trazer a "prata" para o primeiro verso e passar os "anéis de saturno" para o seguinte, do contrário seria difícil uma construção que fosse inteligível e transmitisse o pertencimento da "prata" aos "anéis de saturno" e às "vias lácteas".

Um leitor curioso, que passou direto pela introdução e correu para a tradução do poema, sendo uma pessoa educada e gentil, apontará para os colegas que há uma palavra absurda na segunda estrofe. Trata-se do monstrengo lexical "pteróquiro". E é justamente com essa dificuldade tradutológica que se exemplifica a discussão a respeito das informações estéticas.

$\mathrm{Na}$ segunda estrofe do original, o leitor encontrará o termo kryloruki. Em nenhum dos dicionários consultados, foi encontrada uma definição da palavra. Separando as partes que compõe o neologismo, há duas raízes justapostas: a primeira, kryló, significa "asa"; a segunda, ruká, "mão" ou "braço", e a partir dessa justaposição, o poeta forma um adjetivo. Praticamente, intraduzível para o português, exceto com a criação de um pungente neologismo ilógico. No entanto, 
encontra-se no dicionário, a palavra rukokrýly, que significa "morcego". Fica claro que rukokryly é a base do neologismo, e Biély haveria invertido a ordem dos radicais cunhando a palavra kryloruki, respeitando a regra de ortografia russa que impede o uso do "i duro (y)" depois da letra "k". Na tradução, não se toma a palavra "morcego" como base, pois causa riso ler "cegomor"; mas, sim, o nome de sua ordem taxonômica: chiroptera, dado pela formação anatômica das asas - em grego, pterón - a partir dos longos dedos das mãos - em grego, cheir - do animal, entre os quais há uma membrana que forma a asa. Logo, a ordem dos radicais é exatamente a mesma do russo. Então pegamos essa palavra, ou melhor, não propriamente a nomenclatura científica, mas o adjetivo "quiróptero", que é o aportuguesamento dela. Aplica-se, então, o mesmo procedimento utilizado por Biély, a inversão dos radicais, e chegamos ao adjetivo: "pteróquiro".

Com razão, o leitor torceria o nariz diante da estranha palavra. Mas, como diz Boris Schnaiderman, "Uma das grandes dificuldades da tradução consiste em procurar, na língua de chegada, o correspondente à estranheza, tão frequente nos grandes textos literários." (SCHNAIDERMAN, 2011, p. 69). Não é fácil mensurar o grau de estranhamento causado por esta ou aquela palavra no leitor de uma ou outra língua. Porém não é difícil perceber de maneira binária se ele existe ou não. A ausência de rukokryly em diversos dicionários é um indício de o leitor estranhar sua aparição no papel, embora não seja uma rejeição completa como a opção "cegomor”.

Assim, o bizarro "pteróquiro" também é, ao mesmo tempo, estranho e familiar. Schnaiderman concorda com Campos ao afirmar que focar na precisão semântica "torna muitas vezes o texto explicativo e duro demais." (SCHNAIDERMAN, 2011, p. 31). No nosso exemplo, seria possível traduzir a palavra rukokryly por "mão-alados", como fez Gerard Shelley em sua tradução para o inglês. Porém, essa solução não reproduz o processo de derivação utilizado por Andrei Biély para formar o neologismo.

Entretanto, para fazer uma tradução que reproduza todos os procedimentos e elementos do original, seria necessário criar uma obra coincidente em tantos aspectos que se acabaria por escrever novamente o original, tarefa só permitida a Pierre Menard. Para nós, os outros, restam estas acalentadoras palavras: “O poeta exprime (ou quer exprimir) o inexprimível, o pintor reproduz o irreproduzível, o estatuário fixa o infixável. Não é surpreendente, pois, que o tradutor se empenhe em traduzir o intraduzível." (RÓNAI, 2012, p. 17). 


\section{Terra Natal}

Soluça, elemental relâmpago, em colunas de fogo trovejante!

Rússia, Rússia, Rússia, cremando-me, enlouquece!

Nas tuas fatídicas ruínas, nos teus surdos abismos, derramam os pteróquiros espíritos seus resplandecentes onirismos.

Não choreis: ajoelhai-vos frente ao turbilhão de chamas, ao trovão das canções seráficas, ao dilúvio das cósmicas semanas!

Descendido, Cristo consolará, com o raio de Seu inefável olhar, os secos desertos da infâmia e os mares de afogadas lágrimas.

Mesmo que haja no céu prata dos anéis de Saturno e das vias lácteas, borbulha em fosfórica tempestade, núcleo ígneo da Terra.

E tu, elemento flamejante, Cremando-me, enlouquece, Rússia, Rússia, Rússia, és o messias do dia que virá!
Рысай, буревая стихия, В столбах громового огня! Россия, Россия, Россия, Безумствуй, сжигая меня!

В твои роковые разрухи, В глухие твои глубины, Струят крылорукие Аухи Свои светозарные сны.

Не плачьте: склоните колени Туда - в ураганы огней, В грома серафических пений, В потоки космических Аней!

Сухие пустыни позора, Моря неизливные слёз Аучом безглагольного взора Согреет сошедший Христос.

Пусть в небе - и кольца Сатурна, И млечных путей серебро, Кипи фосфорически-бурно, Земли огневое яАро!

И ты, огневая стихия, Безумствуй, сжигая меня, Россия, Россия, Россия Мессия гряАущего Аня! 


\section{Referências}

BÍBLIA. Bíblia Sagrada Ave-Maria. São Paulo: Editora AveMaria, 1959.

BIÉLY, Andrei. Sobranie sotchinieni. Stikhotvororienia i poemy. Moskva: Respublika, 1994.

CAMPOS, Haroldo et al. Poesia Russa Moderna. Rio de Janeiro: Civilização Brasileira, 1968.

CARPEAUX, Otto Maria. História da Literatura Ocidental. São Paulo: Leya, 2011.

MELETÍNSKI, E. M. Os Arquétipos Literários; tradução Aurora Fornoni Bernardini, Homero Freitas de Andrade, Arlete Cavaliere. Cotia: Ateliê Editorial, 2015.

NOYCE, John. Sophia and the Mystical Tradition. S.l.: s.n., 2012.

RÓNAI, Paulo. Escola de Tradutores. Rio de Janeiro: José Olympio, 2012.

ROSENTHAL, Bernice. Eschatology and the Appeal of Revolution: Merezhkovsky, Bely, Blok. In: California Slavic Studies, Vol. 11, 1980, pp. 105-141.

TERRAS, Victor. Handbook of Russian Literature. New Haven: Yale University Press, 1985. 